\title{
Alkol/madde kullanım bozukluğu olan hastalarda laboratuvar parametrelerinin karşılaştırılması
}

\section{Comparison of Laboratory Parameters in Patients with Alcohol / Substance Use Disorder}

iD Bahadır Demir' $^{1}$ iD Filiz Özsoy ${ }^{2}$

${ }^{1}$ Gaziantep Üniversitesi, Tip Fakültesi, Psikiyatri ABD, Gaziantep

${ }^{2}$ Tokat Devlet Hastanesi, Psikiyatri Kliniği, Tokat

$\ddot{0} \mathbf{z}$

Amaç: Çalışmamızda alkol/madde kullanım bozukluğu (AMKB) tanılı hastalarda bazı laboratuvar parametrelerini hem birbirleri arasında hem de sağlıklı kontrol grubu ile karşılaștırarak incelemektedir.

Gereç ve Yöntem: Çalışmaya Gaziantep 25 Aralık Devlet Hastanesi AMATEM (Alkol ve Madde Bağımlılığı Tedavi Merkezi) servisinde yatarak tedavi gören DSM-5 kriterlerine göre opioid, metamfetamin, alkol, çoklu madde kullanım bozukluğu tanılı hastalar alındı. Toplamda 729 kişi; 612 kişi hasta grubu ve 117 kişi sağlıklı kontrol grubu olarak dahil edildi. Katılımcıların hastane sisteminden geriye dönük olarak laboratuvar parametreleri incelendi.

Bulgular: Çalışmamıza alınan katılımcılardan 23 kişi kadın iken 706 kişi erkek idi. Genel yaş ortalaması 40.91 \pm 29.58 yıl olarak hesaplandı. Laboratuvar parametreleri incelendiğinde kan elektrolit düzeylerinden sodyum değeri opioid, metamfetamin, çoklu madde kullanım bozukluğu olan hastalarda sağliklı kontroller ve alkol kullanım bozukluğu olan hastalara göre daha yüksekti $(\mathrm{P}<0.001)$. Opioid, metamfetamin, çoklu madde kullanım bozukluğu olan hastalarda potasyum düzeyi sağlıklı kontroller ve alkol kullanım bozukluğu olan hastalara göre daha yüksekti $(\mathrm{P}<0.001)$. Alkol kullanım bozukluğu olan hastalarda karaciğer enzimleri (aspartat aminotransferaz (AST), alanin amino transferaz (ALT), gama glutamil transferaz (GGT)) diğer gruplara göre yüksek iken üre değeri ise düşük olarak saptandı.

Sonuç: Sonuçlarımızda alkol/madde kullanım bozukluğu olan hastaların karaciğer enzimleri, böbrek fonksiyonları ve elektrolit düzeyleri ile kan lipid profillerinin etkilendiğ gösterilmiştir. Elde ettiğimiz sonuçlara dayanarak alkol/madde kullanım bozukluğu olan hastaların tekli ya da çoklu organ hasarlarının, yapısal ve fonksiyonel etkilenmelerinin olabileceği tedavi planlarında göz önüne alınmalıdır.

Anahtar kelimeler: Alkol kullanım bozukluğu, madde kullanım bozukluğu, üre, kreatinin, elektrolitler.

Abstract

Objective: In our study, we aimed to investigate some laboratory parameters in patients diagnosed with alcohol / substance use disorder (ASUD) by comparing with a healthy control group.

Material and Methods: Patients diagnosed with opioid, methamphetamine, alcohol, and multiple substance use disorders according to DSM-5 criteria who were hospitalized in Gaziantep State Hospital Alcohol and Substance Addiction Treatment Center (AMATEM) service on December 25 were included in this study. Study group consisted of 612 patients while the control group consisted of 117 healthy subjects. Laboratory parameters of the participants were analysed retrospectively from the hospital data.

Results: Among the participants included in our study, 23 patients were female, while 706 were male. Mean age was $40.91 \pm 29.58$ years. Blood electrolyte levels of sodium were higher in patients with opioid, methamphetamine, and multiple substance use disorders compared to healthy controls and patients with alcohol use disorder ( $\mathrm{P}<0.001)$. In patients with opioid, methamphetamine, and multiple substance use disorder, potassium levels were higher than healthy controls and patients with alcohol use disorder $(\mathrm{P}<0.001)$. In patients with alcohol use disorder, liver enzymes (aspartate aminotransferase (AST), alanine aminotransferase (ALT), gamma glutamyl transferase (GGT)) were found to be higher than other groups, while urea value was found to be low.

Conclusion: Our results showed that liver enzymes, kidney functions, electrolyte levels, and blood lipid profiles of patients with alcohol / substance use disorder were affected. Based on the results we obtained, it should be taken into consideration in treatment schedules that patients with alcohol / substance use disorder may have single or multiple organ damage and/or structural and functional effects.

Keywords: Alcohol use disorder, substance use disorder, urea, creatinine, electrolytes

Yazışma Adresi: Bahadır Demir, Gaziantep Üniversitesi, Tıp Fakültesi, Psikiyatri ABD, Gaziantep.

E-Posta: bahadirdemir23@gmail.com

Alınma tarihi: 22.12.2020 / Kabul tarihi: 25.04.2021 / Yayımlanma tarihi: 15.12.2021

Madde kullanım bozukluklarında biyokimyasal laboratuvar

Genel Tip Derg 2021;31(4)360-364

parametreleri - Demir ve Özsoy. 
Alkol/Madde Kullanım Bozukluğu (AMKB); tüm alınan tedbirlere rağmen giderek artan bir halk sağlığı sorunudur (1). Dünya Sağlık Örgütü'nün verilerine göre 2015 yılında dünya nüfusunun \%5'i en az bir kez herhangi bir maddeyi denemiştir. Yapılan raporlamada Dünya nüfusunun \%0.6'sında madde kullanım bozukluğu olduğu saptanmıştır (2). AMKB hem sıklığı artan hem de kullanma yaşı düşen oldukça ciddi bir hastalıktır (1). Bu hastalık kişinin beden, ruh sağlığını, yaşam kalitesini, güvenliğini bozmakta ve topluma da maliyeti oldukça yüksek olmaktadır (3).

Literatürde AMKB hastalarında yapılan çalışmalarda; serum elektrolit ve enzim değerlerinin etkilendiği gösterilmiştir (46). Yapılan bir çalışmada; opioid kullanım bozukluğu olanlarda hemoglobin, hematokrit değerlerinin düştüğü ve opioid kullanımının anemiye yol açabildiği gösterilmiştir (4). Başka bir çalışmada ise; alkol kullanım bozukluğu olan hastalarda platelet değerlerinin düşük, karaciğer enzimlerinin yüksek olduğu saptanmıştır (7). Yine AMKB tanılı hastalarda yapılan bir çalışmada tedavi öncesi ve sonrası kan elektrolit, karaciğer enzim düzeylerinin ve böbrek fonksiyonlarının değiştiği bildirilmiştir (8). Hastaların laboratuvar parametrelerinin bozulması beraberinde tıbbi komplikasyonların gelişmesine yol açabilmektedir (4-6). Hem alkol/madde kullanımı hem de gelişen komplikasyonlarla ikincil ülkelerin ekonomik ve sosyal durumlarında bozulmalar ortaya çıkabilir (7).

AMKB hastalarında laboratuvar parametrelerinde bozulma hastaların genel durumlarında bozulmaya ve komplikasyonların gelişmesine yol açabilmektedir (4-6). AMKB hastalarında laboratuvar parametrelerinin hem tedavi planlamasinda, hem de komplikasyonların aydınlatılması ve tedavi edilmesinde göz önünde bulundurulması gerekmektedir. Tüm bu bilgiler 1şı̆̆ında çalışmamızda AMKB tanılı hastalarda laboratuvar parametrelerini hem hastaları birbirileri arasında hem de kontrol grubu ile karşılaştırarak incelemeyi amaçladık.

\section{Gereç ve Yöntem}

Çalışma retrospektif olarak yapıldı. Çalışma örneklemini 01.01.201931.12.2019 tarihleri arasında 25 Aralık Gaziantep Devlet Hastanesi AMATEM (Alkol ve Madde Bağımlılı̆̆ı Tedavi Merkezi) kliniğinde yatarak tedavi gören DSM-5 kriterlerine göre madde kullanım bozukluğu tanısı konulan hastalar ve madde kullanımı olmayan, psikiyatrik tanı ölçütlerini karşılayacak bir hastalığı olmayan kişiler oluşturdu. Opioid, çoklu madde, metamfetamin ve alkol kullanım bozukluğu tanılı hastalar çalışmamıza dahil edildi. Madde kullanım bozukluğu dışında başka bir psikiyatrik hastalığı olmayan kişiler çalışmaya alınmadı. Hastaların tedavi öncesi, hastane yatışlarının ilk günü antekubital venden alınan kan örneklerinde; üre, kreatinin, aspartat aminotransferaz (AST), alanin amino transferaz (ALT), gama glutamil transferaz (GGT) enzim aktiviteleri, total kolesterol, HDL kolesterol, LDL kolesterol, trigliserid (TG), kan elektrolit düzeyleri gibi biyokimyasal değerleri incelendi. Beraberinde hastalar ile yaş, cinsiyet gibi demografik verilerle eşleşebilecek, hali hazırda ve öncesinde tanı almış herhangi bir psikiyatrik hastalığı ve alkol/madde kullanımı olmayan kişiler sağlıklı kontrol grubu olarak çalışmaya dahil edildi. Sağlıklı kontroller; sağlık kurulunda muayene edilip psikiyatrik tanı ölçütlerini karşılayacak bir hastalığı ve tıbbi herhangi bir hastalığı olmayan kişiler arasından seçildi ve bu kişilerin
Çalışmanın yapılabilmesi için Sanko Üniversitesi Klinik Araştırmalar Yerel Etik Kurulu'ndan onay alındı. Çalışma Helsinki Deklarasyonu'na uygun şekilde yürütüldü.

\section{Veri Toplama Araçları}

Sosyodemografik veri formu: Tüm katılımc1ların dosyaları üzerinden yaş, cinsiyet, öncesinde AMATEM kliniğinde yatarak tedavi alımı olup olmadığı, kullandıkları tedaviler, tedavi almalarını gerektirir tıbbi hastalıklarının olup olmadığı kayıt edildi. Ek olarak aldıkları maddeleri kaç yıldır aldıkları, ne kadar zaman madde almadan kalabildikleri gibi klinik değerlendirme bilgileri de eklenmiştir.

İstatistiksel analiz:

Hesaplamalarda hazır istatistik yazılımı SPSS for Windows 22 (Statistical Package for Social Sciences for Windows 22) kullanıldı. Verilerin normallik dağılımları Kolmogorov-Smirnov testi ile analiz edildi. Kategorik veriler sayı ve yüzde olarak, sayısal veriler ortalama \pm standart sapma olarak gösterildi. Hastaların kategorik verilerinin karşılaştırmalarında Ki-kare testi, sayısal verilerin gruplar arasında karşılaştırmalarında ise normal dağ 1 lıma uyan değişkenler için Tek Yönlü Varyans Analizi (One Way ANOVA), normal dağılıma uymayan değişkenler için Kruskal Wallis testi kullanıldı. Farklılığın hangi gruptan kaynaklandığını belirlemek için yapılan çoklu karşılaştırmada normal dağılıma uyan değişkenlerde Tukey, normal dağılma uymayan değişkenlerde Mann-Whitney $U$ testi yapıldı. Çalışmamızda tüm analizlerde $\mathrm{p}<0.05$ hesaplandığında istatistik olarak anlamlı kabul edildi.

\section{Bulgular}

Çalı̧̧mamıza dahil edilme kriterlerini karşılayan 612 hasta, 117 sağlıklı kontrol alındı. Hastaların tanıları sırası ile; 296 kişi (\%40.60) opioid, 180 kişi (\%24.69) çoklu madde, 83 kişi (\%11.38) metamfetamin, 43 kişi (\%5.89) alkol, 10 kişi (\%1.37) esrar ve sentetik kannabinoid kullanım bozukluğuydu. Katılımcıların genel özellikleri incelendiğinde; toplamda 23 kişi kadın iken 706 kişi erkekti. Katılımcıların yaş ortalaması; $40.91 \pm 29.58$ yıl olarak hesaplandı. Katılımcıların demografik özellikleri Tablo 1'de sunulmuştur. Sağlıkı kontrol grubunun tedavi almasını gerektirir ek tıbbi hastalığı yoktu. Hasta grubunda ise 569 kişide (\%92.97) tedavi almasını gerektiren hastalık yok iken; 43 (\%7.02) kişinin ek hastalığ1 vardı. On beş kişide (\%35) kronik akciğer hastalığı (astım, kronik obstruktif akciğer hastalığı gibi), 6 kişide (\%14) kronik iskemik kalp hastalığı, 6 kişide (\%14) hipertansiyon, 4 kişide (\%9.30) sedef hastalığı, 3 kişide (\%7) otoimmun hastalık ve 3 kişide (\%7) epilepsi hastalığı bulunmaktaydı. Diğer kişilerde ise; döküntülü cilt hastalığı, tedavisi tamamlanmış malignite, trombofilebit ve damar rahatsızlıkları mevcuttu. Hastaların madde almadan geçirdikleri zaman ay olarak; opioid kullanım bozukluğu olanlar için 7.46 \pm 13.70 , metamfetamin kullanım bozukluğu olanlar için $3.35 \pm 8.55$, çoklu madde kullanım bozukluğu olanlar için $5.38 \pm 8.92$ ve alkol kullanım bozukluğu olanlar için $4.55 \pm 6.38$ olarak hesapland1. Daha önce hastanede yatırılarak tedavi edilme sayıları incelendiğinde ise; opioid kullanım bozukluğu olanlarda $1.49 \pm 1.68$, metamfetamin kullanım bozukluğu olanlarda $0.31 \pm 0.85$, çoklu madde kullanım bozukluğu olanlarda $1.0 \pm 1.27$ ve alkol kullanım bozukluğu olanlarda $2.16 \pm 2.78$ ' di. 
Tablo 1. Katılımcıların sosyodemografik özellikleri

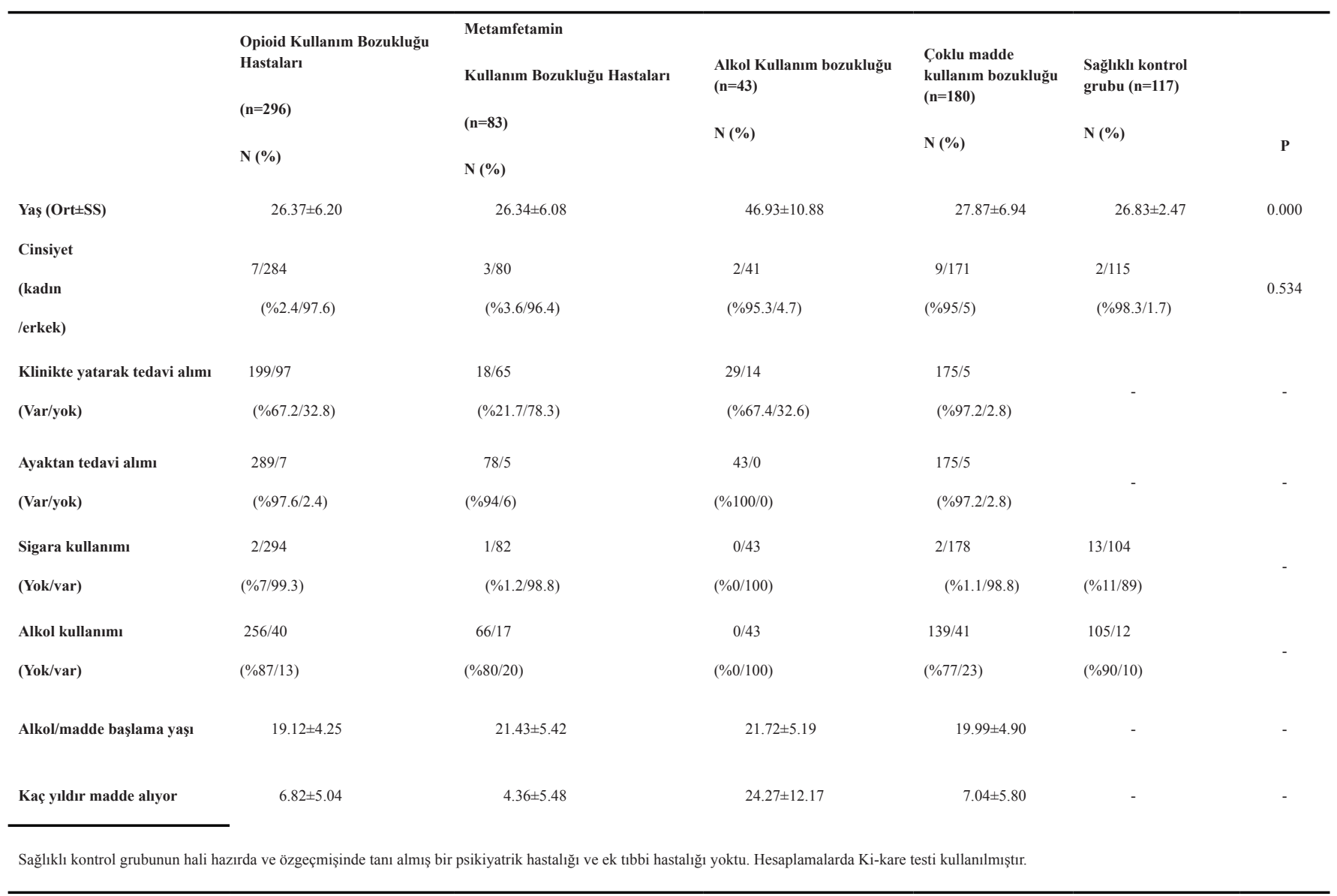

Katılımcıların laboratuvar parametrelerinden kan elektrolit düzeyleri incelendiğinde; sodyum değeri opioid, metamfetamin, çoklu madde kullanım bozukluğu olan hastalarda sağlıklı kontroller ve alkol kullanım bozukluğu olan hastalara göre anlamlı daha yüksekti $(\mathrm{F}=14.651, \mathrm{P}<0.001)$. Benzer şekilde kan potasyum değeri; opioid, metamfetamin, çoklu madde kullanım bozukluğu olan hastalarda sağlıklı kontroller ve alkol kullanım bozukluğu olan hastalara göre istatistiksel anlamlı yüksek bulundu $(\mathrm{F}=16.938 ; \mathrm{P}<0.001)$. Diğer laboratuvar parametreleri ise Tablo 2'de verilmiştir.

\section{Tartışma}

Çalışmamızda, AMKB tanılı hastalarda laboratuvar parametrelerini hem birbirileri arasında hem de kontrol grubu ile karşılaştırarak inceledik. Sonuçlarımızda; kan elektrolit düzeylerinde sodyum değeri opioid, metamfetamin, çoklu madde kullanım bozukluğu olan hastalarda sağliklı kontroller ve alkol kullanım bozukluğu olan hastalara göre daha yüksekti. Kan potasyum değeri de benzer şekilde; opioid, metamfetamin, çoklu madde kullanım bozukluğu olan hastalarda săglıklı kontroller ve alkol kullanım bozukluğu olan hastalara göre yüksek olarak tespit edilmiştir. Metamfetamin kullanım bozukluğu olan hastalarda kalsiyum değeri diğer gruplara göre düşüktü. Karaciğer enzimleri alkol kullanım bozukluğu olan hastalarda diğer gruplara göre yüksekti. Böbrek fonksiyonlarından üre değeri yine alkol kullanım bozukluğu olan hastalarda düşük olarak saptandı. Son olarak alkol kullanım bozukluğu olan hastalarda kolesterol değeri diğer gruplardan yüksek tespit edildi.

Literatür ile uyumlu olarak alkol kullanım bozukluğu hastalarında karaciğer enzimleri (AST, ALT, GGT) diğer gruplardan yüksek olarak saptanmıştır $(7,9,10)$. Yağlı karaciğerden siroz ve komplikasyonlarına kadar ilerleyebilen klinik-histolojik bir spektrum; alkolik karaciğer hastalığı olarak tanımlanmaktadır. Tüm dünyada alkol kullanımı kronik karaciğer hastalığının başlıca nedenlerinden biri olarak gösterilmektedir (11). Alkolik karaciğer hastalığına özgü bir biyobelirteç olmasa da AST, ALT, GGT gibi karaciğer transaminazlarında yükselme olduğu saptanmıştır. Bu transaminaz değerlerinin yükselmesinin alkolik karaciğer hastalığ için uyarıcı olması gerektiği de aynı çalışmada bildirilmiştir (12). Fakat literatürde yapılan çalışmalarda; karaciğer yağlanması, siroz gibi tanı almış bir karaciğer hastalığı olmadan da alkol kullanımına bağlı karaciğer enzimlerinin yükseldiği gösterilmiştir $(9,10)$. Yapılan bir çalışmada remisyonda olan alkol kullanım bozukluğu hastalarının karaciğer enzim değerleri düşerken, nüks olduğunda bu değerlerin yeniden yükseldiği tespit edilmiştir (9). Başka bir çalışmada ise; GGT düzeyleri ile birlikte diğer laboratuvar parametrelerinin de yükseldiği saptanmıştır (10). Bizim sonuçlarımızda benzer nitelikte; medikal tedavi almasını gerektirir karaciğer hastalığı olmayan alkol kullanım bozukluğu tanılı hastalarda transaminazlar yüksek olarak bulunmuştur.

Bağımlılık yapan maddelerin pek çoğunun dolaylı ya da direk etki ile böbrek fonksiyonlarını etkileyebildiği bildirilmiştir (13, 14). $\mathrm{Bu}$ maddeler rabdomiyoliz, interstisyel nefrit, glomerulonefrit gibi böbrek hasarı ortaya çıkarabilmektedir. Bazı durumlarda da akut böbrek hasarı olmadan böbrek fonksiyonlarını bozabilmektedir (15). Literatürde madde kullanımı olan, 16-35 yaş arası dokuz ayrı olgunun 
Tablo 2. Grupların laboratuvar parametrelerinin karşılaştırılması

\begin{tabular}{|c|c|c|c|c|c|c|c|c|}
\hline & $\begin{array}{l}\text { Opioid Kullanım } \\
\text { Bozukluğu Hastaları } \\
\text { (n=296) } \\
(\text { Ort } \pm \text { SS) }\end{array}$ & $\begin{array}{l}\text { Metamfetamin } \\
\text { Kullanım Bozukluğu } \\
\text { Hastaları } \\
(\mathrm{n}=\mathbf{8 3}) \\
(\text { Ort } \pm \text { SS) }\end{array}$ & $\begin{array}{l}\text { Alkol Kullanım } \\
\text { Bozukluğu }(\mathrm{n}=43) \\
\text { (Ort } \pm \text { SS) }\end{array}$ & $\begin{array}{l}\text { Çoklu Madde } \\
\text { Kullanım } \\
\text { Bozukluğu }(n=180) \\
(\text { Ort } \pm \text { SS) }\end{array}$ & $\begin{array}{l}\text { Sağlıklı } \\
\text { Kontrol } \\
\text { Grubu } \\
(\mathrm{n}=117) \\
(\text { Ort } \pm \text { SS) }\end{array}$ & F & $\mathbf{P}$ & $\begin{array}{l}\text { Anlaml fark } \\
\text { (Tukey) }\end{array}$ \\
\hline Üre & $24.64 \pm 6.24$ & $25.70 \pm 6.35$ & $19.58 \pm 6.66$ & $26 \pm 6.32$ & $24.53 \pm 5.76$ & 7.87 & $<0.001$ & $\begin{array}{l}\text { A-C } \\
\text { B-C } \\
\text { C-A,B,D,E } \\
\text { D-C } \\
\text { E-C }\end{array}$ \\
\hline Kreatinin & $0.74 \pm 0.11$ & $0.78 \pm 0.11$ & $0.73 \pm 0.13$ & $0.75 \pm 0.12$ & $0.73 \pm 0.11$ & 13.85 & $<0.001$ & $\begin{array}{c}\text { A-B,E } \\
\text { B-E } \\
\text { C-E } \\
\text { D-E } \\
\text { E-A.B,C,D }\end{array}$ \\
\hline $\begin{array}{l}\text { Total } \\
\text { kolesterol }\end{array}$ & $140.25 \pm 28$ & $150 \pm 33.1$ & $186.14 \pm 37.1$ & $146.33 \pm 38$ & $159.11 \pm 30$ & 19.63 & $<0.001$ & $\begin{array}{l}\text { A-C,E } \\
\text { B-C } \\
\text { C-A,B,D,E } \\
\text { D-C,E } \\
\text { E-A,C,D }\end{array}$ \\
\hline LDL-K & $75.72 \pm 23.84$ & $77.46 \pm 27.54$ & $90.19 \pm 35$ & $80 \pm 30.65$ & $90.44 \pm 26$ & 6.773 & $<0.001$ & $\begin{array}{l}\text { A-C,E } \\
\text { B-E } \\
\text { C-A } \\
\text { D-C,E } \\
\text { E-A,B,D }\end{array}$ \\
\hline Sodyum & $143 \pm 2.06$ & $142 \pm 1.9$ & $141 \pm 2.58$ & $142 \pm 2.21$ & $140 \pm 2.33$ & 14.65 & $<0.001$ & $\begin{array}{l}\text { A-C,E } \\
\text { B-E } \\
\text { C-A } \\
\text { D-E } \\
\text { E-A,B,D }\end{array}$ \\
\hline Potasyum & $4.89 \pm 0.4$ & $4.81 \pm 0.35$ & $4.44 \pm 0.58$ & $4.86 \pm 0.46$ & $4.52 \pm 0.32$ & 16.93 & $<0.001$ & $\begin{array}{l}\text { A-C,E } \\
\text { B-C,E } \\
\text { C-A,B,D } \\
\text { D-C,E } \\
\text { E-A,B,D }\end{array}$ \\
\hline Kalsiyum & $9.30 \pm 0.44$ & $9.14 \pm 0.17$ & $9.16 \pm 0.38$ & $9.22 \pm 0.41$ & $9.53 \pm 0.39$ & 11.85 & $<0.001$ & $\begin{array}{l}\text { A-B,E } \\
\text { B-A,E } \\
\text { C-E } \\
\text { D-E } \\
\text { E-A,B,C,D }\end{array}$ \\
\hline & & & & & & H & & $\begin{array}{l}\text { Anlamlı fark } \\
\text { (Mann-Whitney U) }\end{array}$ \\
\hline AST* $^{*}$ & $21.57 \pm 13.97$ & $21.41 \pm 16$ & $43.05 \pm 35.7$ & $19.54 \pm 8.90$ & $22.79 \pm 22$ & 34.68 & $<0.001$ & $\begin{array}{l}\text { A-C } \\
\text { B-C } \\
\text { C-A,B,D,E } \\
\text { D-C } \\
\text { E-C }\end{array}$ \\
\hline ALT $^{*}$ & $22.79 \pm 34.12$ & $26 \pm 35.89$ & $35.72 \pm 41.89$ & $20.01 \pm 17$ & $23.75 \pm 14.7$ & 48.63 & $<0.001$ & $\begin{array}{l}\text { A-B,C,D } \\
\text { B-A,C,E } \\
\text { C-A,B,D } \\
\text { D-A,C,E } \\
\text { E-B,D }\end{array}$ \\
\hline GGT* & $21.11 \pm 19.92$ & $19.63 \pm 12.90$ & $170 \pm 196$ & $20.14 \pm 17$ & $19.39 \pm 8.06$ & 101.16 & $<0.001$ & $\begin{array}{l}\text { A-B,C,D } \\
\text { B-A,C } \\
\text { C-A,B,D,E } \\
\text { D-A,C } \\
\text { E-C }\end{array}$ \\
\hline HDL-K* & $43.16 \pm 9.90$ & $45.77 \pm 11.22$ & $68.5 \pm 31$ & $43.40 \pm 14$ & $48.32 \pm 10$ & 25.51 & $<0.001$ & $\begin{array}{l}\text { A-C,E } \\
\text { B-C,E } \\
\text { C-A,B,D,E } \\
\text { D-C,E } \\
\text { E-A,B,C,D }\end{array}$ \\
\hline TG* & $111.20 \pm 53$ & $136.59 \pm 86.57$ & $136.7 \pm 65.7$ & $120 \pm 62$ & $103 \pm 59.24$ & 66.88 & $<0.001$ & $\begin{array}{l}\text { A-B,C,D,E } \\
\text { B-A,E } \\
\text { C-A,E } \\
\text { D-A,E } \\
\text { E-A,B,C,D }\end{array}$ \\
\hline
\end{tabular}

Hesaplamalarda * ile işaretlilerde Kruskall Wallis-H testi diğerlerinde One Way ANOVA-F testi kullanılmıştır. Opioid Kullanım Bozukluğu Hastaları: A, Metamfetamin Kullanım Bozukluğu Hastaları:B, Alkol Kullanım Bozukluğu Hastaları: C, Çoklu Madde Kullanım Bozukluğu Hastaları : D, Sağlıklı Kontrol Grubu: E. 
sunumu yapılmıştır. $\mathrm{Bu}$ olgu serisinde hastaların kan üre değerleri 40.70-124.10; kreatinin değerleri 1.40-10.40 arasında değişmiştir. Bu olguların böbrek fonksiyonlarındaki bozulma için semptomatik tedavi almaları gerekmiştir (15). Kreatinin değeri; böbrek fonksiyonlarını değerlendirmede hem ucuz hem de kolay değerlendirilen bir belirteç olarak gösterilmektedir. Fakat; renal hasarda morbidite ve mortaliteyi göstermede serum kreatinin değeri yeterli olarak gösterilmemektedir. Ek olarak üre değeri ya da ileri belirteçler de çalışılmalıdır (16). Kan üre değeri böbrek fonksiyonlarındaki bozulma ile değişmektedir. Kalp yetmezliği, ateş, travma gibi durumlarda ve alkol-madde kullanım bozukluğu gibi hastalıklarda kan üre düzeyi değişebilmektedir (17). Bizim sonuçlarımızda da hastaların tanı almış böbrek fonksiyon bozukluğu olmasa da; metamfetamin, opioid ve çoklu madde kullanımı olan hastaların kreatinin değerleri alkol kullanımı olan hastalar ve sağlıklı kontrollerden yüksek saptanmıştır. Üre değeri ise alkol kullanım bozukluğu olan hastalarda sağlıklı kontrollerden düşük iken diğer gruplar arasında anlamlı farklılık göstermemiştir. Elde ettiğimiz bu sonuçla, alkol-madde kullanımının böbrek fonksiyonlarını az ya da çok etkileyebildiği sonucuna varılmıştır. Böbrek fonksiyonlarındaki bu değişimle birlikte kan elektrolit değerleri de yine opioid, metamfetamin ve çoklu madde kullanım bozukluğu olan hastalarda yükselmiş olarak bulunmuştur.

Madde kullanım bozukluğunda; serum total kolesterol ve trigliserid düzeylerinin değiştiği bildirilmiştir. Merkezi sinir sisteminde bağımlılık gelişmesinde kan lipid seviyelerinin rolü olabileceği gösterilmiştir (18). Fakat literatürde yapılan çalışmaların sonuçları çelişkili olmuştur (18-20). Yapılan bir çalışmada; opioid kulanım bozukluğu olan hastalar sağlıklı kontroller ile karşılaştırılmıştır. Elde edilen sonuçlarda; total kolesterol düzeyleri hastalarda kontrollere göre anlamlı olarak yüksek bulunmuştur (19). Başka bir çalışmada ise sentetik kannabinoid kullanımı olan hastalar ve opioid kullanımı olan hastalar sağlıklı kontroller ile karşılaştırılmıştır. Her iki hasta grubunun da trigliserid düzeylerinin anlamlı olarak düşük olduğu görülmüştür (20). Metamfetamin kullanım bozukluğu olan hastalarda ise; total kolesterol ve trigliserid düzeylerinin düşük olduğu bildirilmiştir (18). Bizim sonuçlarımızda da benzer şekilde çoklu madde alımı ve opioid kullanım bozukluğu olan hastaların total kolesterol ve HDL-kolesterol düzeyleri sağlıklı kontrollerden düşüktü. Trigliserid düzeyleri ise alkol ve herhangi bir madde alımı olan hastalarda sağlıklı kontrollerden yüksekti. Ek olarak alkol kullanım bozukluğu olan hastaların total kolesterol, trigliserid ve HDL-kolesterol düzeyleri sağlıklı kontroller ve diğer hastalardan yüksekti. Literatürde aralıklı alınan alkolün kolesterol düzeylerini düşürdüğü bildirilmiştir (21). Başka bir çalışmada ise alkol alımının karaciğer lipid profilini bozduğu gösterilmiştir (22). Bizim sonuçlarımızda da bu çalışmaya benzer şekilde alkol kullanımı olan hastaların lipid profillerinin sağlıklı kontrollere göre bozulmuş olduğu görülmüştür.

Elde ettiğimiz sonuçlar bazı kısıtlılıklar göz önüne alınarak değerlendirilmelidir. Bu kısıtlılıklar; cinsiyetler arası dağılımının eşit olmaması, çalışmanın retrospektif nitelikte olması ve bazı laboratuvar parametrelerinin değerlendirilmemiş olması olarak sayılabilir. Ayrıca alkol kullanım bozukluğu olan hastaların alkol kullanım sürelerinin diğer madde kullanım bozukluğu olan hastaların madde kullanım sürelerinden çok daha uzun olması elde edilen sonuçların sadece maruz kalınan maddenin özelliklerine bağlı olarak yorumlanmasını güçleştirmektedir. Bu kısıtlllıklar elde ettiğimiz sonuçların genellemesi ve yorumlamasını sınırlamaktadır. Elde etiğimiz bulguların önem kazanabilmesi için daha büyük örneklem gruplarında daha ileri araştırmalar yapılmasına gerek vardır.

Sonuç olarak alkol/madde kullanım bozukluğu olan hastaların karaciğer enzimleri, böbrek fonksiyonları ve bağlantılı elektrolit düzeyleri ve kan lipid profillerinin etkilendiği gösterilmiştir. Elde edilen bu laboratuvar sonuçlarına dayanarak alkol/madde kullanım bozukluğu olan hastaların tekli ya da çoklu organ hasarlarının, yapısal ve fonksiyonel etkilenmelerinin olabileceği göz önüne alınmalıdır. Hastaların değerlendirilmesinde ve tedavilerinin düzenlenmesinde alkol/madde kullanım bozukluğunda görülen bu biyokimyasal özellikler akılda tutulmalıdır.

\section{Kaynaklar}

1. Merikangas KR, He JP, Burstein M, Swanson AS, Avenovoli S, Cui L, et al. Lifetime prevalence of mental disorders in US adolescents: Results from the National Comorbidity Survey Replication-Adolescent Supplementation (NCS-A). J Am Acad Child Adolesc Psychiatry 2010;49(10): 980-9.

2. World Health Organization. Global status report on alcohol and health. Wold Drug Report (2017)

3. Koç A, Erim BR, Boztaş MH. Madde kullanım bozukluğunda bölgesel farklılıkların etkisi. Anadolu Psikiyatri Derg 2020;21:61-9.

4. Çatak Z. Opioid Bağımlısı Erkek Hastalarda Bazı Hematolojik Parametrelerin Değerlendirilmesi. FÜ Sağlık Bilimleri Tıp Derg 2017;31(2):79-82.

5. Shahabinejad G, Sirati-Sabet M, Kazemi-Arababadi M, Nabati S, Asadikaram G. Effects of opium addiction and cigarette smoking on hematological parameters. Addict Health 2016; 8: 179-85.

6. Begum MS, Saradamma B, Reddy VD, Padmavathi P, Maturu P, Ellutla N, et al. Influence of green tea consumption on cigarette smoking-induced biochemical changes in plasma and blood. Clin Nutrit Exper 2017;16:1-12.

7. Müberra K. Alkol-Madde Bağımlılarının Kan Parametrelerinin Kıyaslanması. Cyprus Turkish J Psychiatry Psychol 2019; 1: 47-9.

8. Barzehkar S, Gozashti MH, Divsalar K, Mashrouteh M, Darvishi-Lardi AH. Investigating Changes in Serum Biochemical Parameters in Opium Addicts Before and During Addiction Treatment. Addict Health 2016;8: 211-7.

9. Akpınar A, Çevik M, Bağcıŏlu E. Erkek alkol bağımlılığında nüks ile biyokimyasal etmenler arasındaki ilişki var mıdır? Kocatepe Tıp Derg 2014;15: 238-45.

10. Salıș O, Akpınar A. Alkol bağımlılığında Gama Glutamin Transferaz (GGT) düzeyinin kan biyokimyasal testleri ve klinik özellikler ile bağlantısı. Sağlık Bilimleri Enstitüsü Derg 2011; 2.

11. Cengiz O, Bengi G. Alkolik Karaciğer Hastalıkları. Güncel Gastroenterol 2019;23: 65-71.

12. Lackner C, Spindelboeck W, Haybaeck J, Douschan P, Rainer F, Terraciono L, et al. Histological parameters and alcohol abstinence determine long-term prognosis in patients with alcoholic liver disease. J Hepatol 2017;66:610-8.

13. Perazella MA, Markowitz GS. Drug-induced acute interstitial nephritis. Nature Rev Nephrol 2010;6:461-70.

14. Kosmadakis G, Michail O, Filiopoulus V, Papadopoulopu P, Michail S. Acute kidney injury due to rhabdomyolysis in narcotic drug users. Int J Artif Organs 2011;34:584-8.

15. Şit D, Kayabașı H, Karagöz F, Karagöz YA, Savaş A. Uyușturucu Madde Kullanımına Bağlı Akut Böbrek Hasarı: Olgu Serisi. J Acad Res Med 2017; 7: 1.

16. Koçan H, Yıldırım Ş, Özdemir E. Böbrek Biyobelirteçleri. İstanbul Kanuni Sultan Süleyman Tıp Derg 2016; 8: 71-74.

17. Pagana KD, Pagana TJ. Mosby's Diagnostic and Laboratory Tests. Mosby Incorporated 2002 .

18. Zhang M, Lv D, Zhou W, Ji L, Zhou B, Chen H, et al. The levels of triglyceride and total cholesterol in methamphetamine dependence. Medicine 2017; 96:e6631.

19. Divsalar K, Meymandi MS, Afarinesh M, Zarandi MM, Haghpanah T, Keythanfar F, et al. Serum biochemical parameters following heroin withdrawal: an exploratory study. Am J Addict 2014;23:48-52.

20. Kouros D, Tahereh H, Mohammadreza A, Minoo MZ. Opium and heroin alter biochemical parameters of human's serum. Am J Drug Alcohol Abuse 2010;36:135-9.

21. Huang S, Li J, Shearer GC, Lichtenstein AH, Zheng X, Wu Y, et al. Longitudinal study of alcohol consumption and HDL concentrations: a community-based study. Am J Clin Nutr 2017;105: 905-12.

22. You M, Arteel GE. Effect of ethanol on lipid metabolism. J Hepatol 2019;70: 237 48. 